EPJ Web of Conferences 34, 01002 (2012)

DOI: 10.1051/epjconf/20123401002

(C) Owned by the authors, published by EDP Sciences, 2012

\title{
Pierre and Astromol
}

\author{
Cecilia Ceccarelli ${ }^{1, a}$
}

UJF-Grenoble 1 / CNRS-INSU, Institut de Planétologie et d'Astrophysique de Grenoble (IPAG) UMR 5274, Grenoble, F-38041, France

\begin{abstract}
This is my tribute to Pierre and his role in creating and keeping alive our group, Astromol.
\end{abstract}

\section{Introduction}

All the story started in December 2002, in the Salle Chartreuse of IPAG. I was going to join LAOG starting from January 2003, LAOG was going to have a new director, Thierry Montmerle, and a new structure with a few large groups. At that time, the ancient group of radioastronomy was almost dismissed. Many had left for joining IRAM, Alain Castets had left to Bordeaux as Director of the Observatoire de Bordeaux and of the Astronomy Laboratory, Bertrand Lefloch was in a two-years detachment in Madrid. Claudine Kahane was almost practically alone working on millimeter astronomy and, what more, she just took the heavy responsibility of the direction of the DEUG of Physics at the University Joseph Fourier of Grenoble. The group of theoretical chemistry, built up at the creation of the IRAM institute to back up it, consisted of two permanent staff members, Pierre and Claire Rist, plus Laurent Wiesenfeld, who formally joined LAOG mid-2003, and some students. In salle Chartreuse, we were, therefore, a few but very enthusiast people who wanted to join their forces to create a new group to pave a new road for the astrochemistry at IPAG. We had no doubts that that was the way to go: millimeter astronomers needed more than ever the expertise of theoretical chemistry people and theoretical chemistry people needed the strong support of a millimeter astrochemistry group. So the discussion was rather about the name of the new group and the name of a group leader, in fact the "pourparler" of the group. We converged fast on the name, Astromol. Then, when it came the moment to decide who was going to be the group leader, each of us indicated the other in front of him/her. We all bursted out, it was fun and it was the imprint of Astromol, a group of people glued together by a shared scientific vision and friendship. It was decided that I was to take the challenge. I have to say that with Pierre, Thierry and Claudine at my sides, my job was greatly eased. The meeting ended up with free-wheel crazy ideas filling up our minds while champagne and foie gras filled up our mouths and stomachs. After almost a decade, Astromol counts a dozen permanent stuff members and several students, more than doubling the sizes at its birth.

The figure shows an emblematic and playful figure that was part of the first public presentation of Astromol: a warrior with two weapons, the astrophysical observations and modeling, and the theoretical chemistry. After almost a decade, we still have this double, interdisciplinary composition and the two sides of Astromol keep feeding each other more than ever. We used to have long discussions of where Astromol should lead for, often around a table with foie gras or fresh cooked pasta and, no doubt, good wine. This brought us towards three large projects: the participation at the European ITN "The Molecular Universe", the scientific participation to the Herschel HIFI project, and the set up of the ANR project "Forcoms". Pierre was a fondamental actor in all these discussions as much

\footnotetext{
a e-mail: Cecilia.Ceccarelli@obs.ujf-grenoble.fr
} 


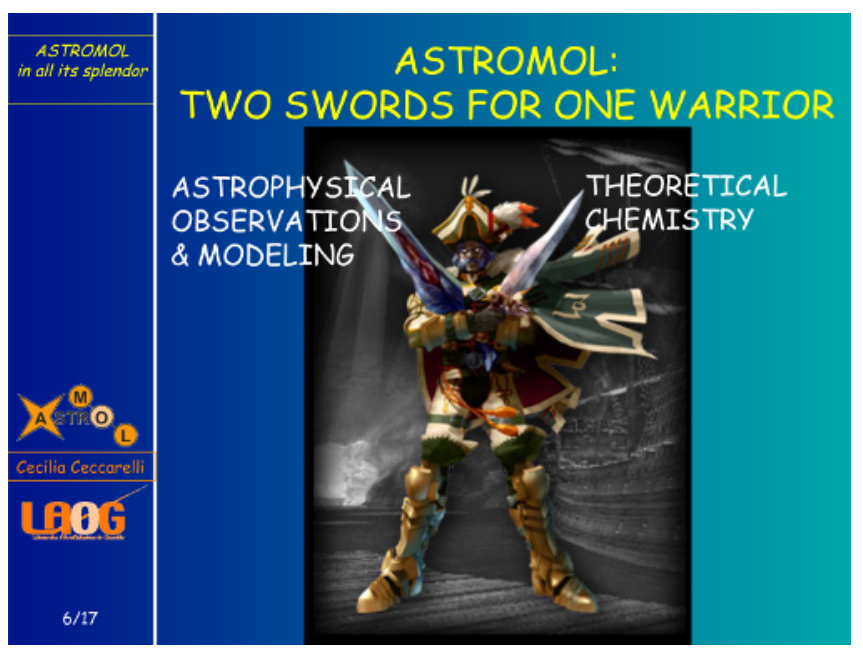

Fig. 1. A playful representation of Astromol, a warrior with two weapons, two swords: the astrophysical obesrvations and modeling, and the theoretical chemistry.

as projects. As one example, I remember Pierre's reluctance in moving towards the problem of interstellar complex organic molecules, as, in his wisdom, he was aware how difficult the problem was and only when we had enough strength and improved skills, he pushed in that direction. He was right in hesitating at first instance and then putting enthusiasm and energy when the project was ready to be tackled. That was the moment, not earlier. It came then the ANR project Forcoms (Formation of Complex Organic Molecules), formulated in 2008 and funded in 2009. Unfortunately, Pierre could not see but the first steps of the project. However, this does not make it less a project born from the intense collaboration within Astromol and, particularly, from the Pierre's invaluable contribution to it.

It has been said elsewhere in this book how Pierre was important in the everyday life, how generous and helpful he was. I want here to acknowledge critical moments for the life of Astromol, and even my own professional and personal life, where Pierre was determinant. We had some moments with exacerbated criticism from or alleged altercation with colleagues, when I felt everything was going to be lost. In those moments, Pierre stepped in with his calm wisdom and savoir-faire suggesting and finding solutions. You could count on him. Always. Astromol has counted on him until the very last days of his life.

Evidently, Pierre was of primordial importance in the birth and life of Astromol and his vision in creating and showing directions for it was correct. My own gratitude to Pierre is immense. He was a teacher, a collaborator, a colleague and, above all, a friend whom I enormously miss. 